\title{
Virtual Tour Univeristas Bina Darma Berbasis Android
}

\author{
Muhammad Soekarno Putra \& Hamim Tezar Rizandi \\ Program Studi Teknik Informatika, Universitas Bina Darma Palembang \\ Email: soekarno@binadarma.ac.id
}

\begin{abstract}
Bina Darma University is one of the private universities located in the city of Palembang. In providing information about the institution, Bina Darma University has used several methods, including websites, brochures, TV streaming, radio and social media such as Instagram and Facebok. However, from several existing media, it turns out that it still doesn't provide information about the location of the room and also the places around the campus. In this case, researchers are interested in making an information media application to introduce the area around the campus by using virtual tour technology with Android-based mobile technology with an offline system so that it will be easier, because it can be accessed using smartphones or other android-based gadgets without a connection. Internet. The applications used in the manufacture of Andoid applications are Unity 3D. The development method used in building this virtual tour application of the MDLC (Multimedia Development Life Cycle).
\end{abstract}

Keywords: Virtual Tour, Unity 3D, Mobile, Android, MDLC

\section{Pendahuluan}

Perkembangan teknologi informasi yang saat ini semakin cepat ternyata menjadi tantangan berat bagi sebuah perusahaan ataupun Perguruan Tinggi, baik itu Negeri maupun Swasta. Teknologi informasi merupakan "perkembangan sistem informasi dengan menggabungkan antara teknologi komputer dengan telekomunikasi” (Budiman, 2017). Diharapkan teknologi informasi dapat dimanfaatkan sebagai penunjang kegiatan operasional dalam menghasilkan suatu informasi. Dengan adanya sistem informasi harus diperhatikan dari segi manfaat, agar hasil yang dicapai nantinya dapat sesuai dengan tujusan untuk memenuhi kebutuhan pengguna teknologi itu sendiri. Maka dari itu sarana penyediaan informasi dalam bentuk media online menjadi hal yang perlu dipersiapkan oleh pihak Perguruan Tinggi agar dapat memenuhi kebutuhan mereka.

Perkembangan teknologi sangatlah berpengaruh pada setiap Perguruan Tinggi. Salah satu Perguruan Tinggi Swasta di Kota Palembang adalah Universitas Bina Darma. Univeristas Bina Darma Palembang telah menggunakan beberapa teknologi dalam mempromosikan ataupun memperkenalkan informasi seputar kampus. Dalam mempromosikan ataupun memperkenalkan institusinya, pihak Universitas telah menggunakan beberapa cara diantaranya website, brosur, tv streaming, radio dan media sosial seperti Instagram, Facebook dan sebagainya.

Universitas Bina Darma Palembang memiliki 4 gedung kampus dengan nama Kampus Utama, Kampus A, Kampus B dan Kampus C. Disetiap gedung memiliki banyak ruangan seperti ruang perkuliahan, ruang laboratorium, ruang perpustakaan dan beberapa ruangan lain yang berkaitan dengan aktivitas kampus. Banyaknya ruangan pada gedung terkadang menjadi sebuah masalah dilingkungan kampus terutama bagi pengunjung ataupun calon mahasiswa yang ingin mendaftar serta mengikuti tes. Beberapa media promosi ataupun media pengenalan serta fasilitas kampus dalam menunjang pemberian informasi letak ruangan serta tempat-tempat disekitar kampus belum terasa memberikan informasi secara praktis dan spesifik. Untuk dapat lebih memperkenalkan lingkungan kampus Universitas 
Bina Darma, peneliti tertarik untuk merancang sebuah aplikasi berbasis android yang berisi lingkungan Universitas Bina Darma Palembang yang kali ini hanya fokus pada satu gedung, yaitu Kampus Utama. Konsep yang akan digunakan dalam pembuatan aplikasi adalah Virtual Tour Berbasis Android.

Virtual Tour adalah "simulasi dari sebuah lokasi yang sesungguhnya, umumnya terdiri oleh sequence atau kumpulan foto" (Fitri, 2016). Virtual Tour merupakan "salah satu teknologi yang bisa memposisikan pengguna berada didalam gambar dan bisa meningkatkan kesadaran situasional dan daya lihat tangkap serta menganalisa data virtual pengguna secara signifikan"(Wulur, 2015). Virtual Tour ini dibuat berbasis Android, karena Android merupakan "salah satu sistem operasi yang paling banyak digunakan untuk perangkat mobile. Dengan kemudahan pemakaiannya dan bersifat open source membuat banyak pengguna dari sistem operasi ini semakin banyak dan sudah menjadi hal yang umum" (Mustika, 2017)

Metode pengembangan yang akan digunakan dalam penelitian ini adalah Multimedia Development Life Cycle (MDLC) (Mustika, 2017). Virtual Tour ini akan menampilkan informasi mengenai lokasi-lokasi lingkungan Universitas yang berbentuk gambar panorama untuk mempresentasikan objek yang luas hingga $360^{\circ}$ yang berguna untuk masyarakat umum terutama mahasiswa. Virtual tour dibuat menggunakan tools Unity 3D sedangkan untuk perancangan sistem menggunakan UML (Unified Modeling Language) dan Flowchart.

\section{Tinjauan Literatur}

\subsection{Virtual Tour}

Virtual Tour adalah sebuah simulasi dari suatu lingkungan nyata, biasanya terdiri dari kumpulan foto panorama, kumpulan gambar yang terhubung oleh hyperlink, ataupun video, atau virtual model dari lokasi yang sebenarnya, serta dapat menggunakan unsur multimedia lain seperti efek suara, musik, dan tulisan. Menurut Osman, Wahab dan Ismail (Daud, Tulenan, \& Najoan, 2016) Virtual Tour merupakan teknologi yang menempatkan user di dalam gambar dan memungkinkan user untuk meningkatkan kesadaran situasional serta meningkatkan daya lihat tangkap dan menganalisa data virtual secara signifikan.

Istilah "virtual tour" sering digunakan untuk menggambarkan berbagai video dan media berbasis fotografi. Kata "panorama" mengindikasikan sebuah pandangan yang tidak terputus, karena panorama bisa berupa sekumpulan foto memanjang ataupun hasil pengambilan video yang kameranya berputar/bergeser. Tetapi istilah "virtual tour" paling sering diasosiasikan dengan virtual tour yang diciptakan dengan foto yang tidak bergerak. Virtual tour dibuat dari sebuah foto yang diambil dari sebuah titik pivot.

\subsection{Unity $3 D$}

Unity $3 D$ atau yang lebih sering disebut sebagai Unity saja, adalah sebuah software pemrograman yang digunakan untuk membuat berbagai macam aplikasi. Mayoritas penggunaan Unity adalah untuk pembuatan aplikasi Game. Tetapi dengan menggunakan Unity, anda dapat membuat berbagai macam aplikasi seperti presentasi, website, bahkan dapat digunakan untuk membuat Augmented Reality (Pamoedji, et al., 2017).

\section{Metode Penelitian}

\subsection{Metode Penelitian}


Metode penelitian yang digunakan oleh peneliti adalah metode deskriptif. Penelitian deskriptif adalah "penelitian yang dirancang untuk memperoleh informasi tentang status suatu gejala saat penelitian dilakukan" (Linarwati dkk, 2017)

\subsubsection{Metode Pengumpulan Data}

1. Wawancara

Wawancara adalah "metode pengumpulan data melalui pertanyaan secara langsung/lisan kepada responden" (Guntara \& Yakub, 2018). Dalam penelitian ini wawancara ditujukan kepada bagian marketing Universias Bina Darma.

2. Observasi

Observasi merupakan "proses penelitian mengamati situasi dan kondisi" (Sugiyono, 2016). Dalam penelitian ini untuk mendapatkan data yang bersifat nyata dan meyakinkan maka peneliti melakukan pengamatan secara sistematis terhadap masalah-masalah yang ada pada lingkungan sekitar.

3. Studi Literatur

Studi Literatur merupakan "metode pengumpulan data dan informasi yang diperoleh melalui sumber-sumber seperti buku, karya tulis, dan sumber lain yang berhubungan dengan objek penelitian"(Kusuma \& Putra, 2016). Pada penelitian ini studi literatur digunakan untuk mendapatkan informasi dan pemahaman literatur melalui berbagai media.

\subsection{Metode Pengembangan}

Metode Pengembangan dalam penelitian ini menggunakan Metode Multimedia Development Life Cycle (MDLC) versi Luther Sutopo. Menurut Nurajizah, 2016 "metode pengembangan ini terdiri dari 6 tahapan yang tersusun secara sistematis sebagai berikut : Konsep (Concept), tahap konsep merupakan tahap awal dalam siklus MDLC. Pada tahap konsep, dimulai dengan menentukan tujuan pembuatan aplikasi serta menentukan pengguna aplikasi tersebut. Perancangan (Design), konsep yang sudah matang akan memudahkan dalam menggambarkan apa yang harus dilakukan. Tujuan dari tahap perancangan adalah membuat spesifikasi secara terperinci mengenai arsitektur proyek, tampilan dan kebutuhan material proyek, serta gaya. Pengumpulan Bahan (Material Collecting), Material Collecting adalah tahap pengumpulan bahan yang sesuai dengan kebutuhan. Bahan-bahan tersebut ialah gambar atau foto yang sudah jadi ataupun yang masih perlu dimodifikasi sesuai dengan kebutuhan yang ada. Atau dengan pemesanan kepada pihak lain sesuai dengan rancangan yang telah dibuat pada tahap sebelumnya. Pembuatan (Assembly), tahap assembly adalah tahap pembuatan keseluruhan bahan multimedia. Aplikasi yang akan dibuat didasarkan pada tahap design, seperti storyboard. Pengujian (Testing), pengujian dilakukan untuk memastikan bahwa hasil pembuatan aplikasi multimedia sesuai dengan rencana. Ada dua jenis pengujian yang digunakan, yaitu pengujian alpha dan pengujian beta. Distribusi (Distribution), tahap ini adalah tahap terakhir dalam siklus pengembangan multimedia. Pendistribusian dapat dilakukan setelah aplikasi dinyatakan layak pakai".

\section{Hasil dan Pembahasan}

4.1 Concept (Konsep) 
Tahap konsep merupakan tahapan awal dalam sebuah perancangan menggunakan Metode MDLC (Multimedia Development Life Cycle). Konsep dalam pembuatan aplikasi ini adalah membuat sebuah aplikasi yang dapat memberikan informasi tentang isi Gedung Universitas Bina Darma. Informasi yang diberikan berupa sebuah gambar panorama 360 dalam bentuk virtual tour. Desain yang menggambarkan proses dan tahapan-tahapan yang akan dilaksanakan dibuat dan dapat dilihat pada gambar 1 .

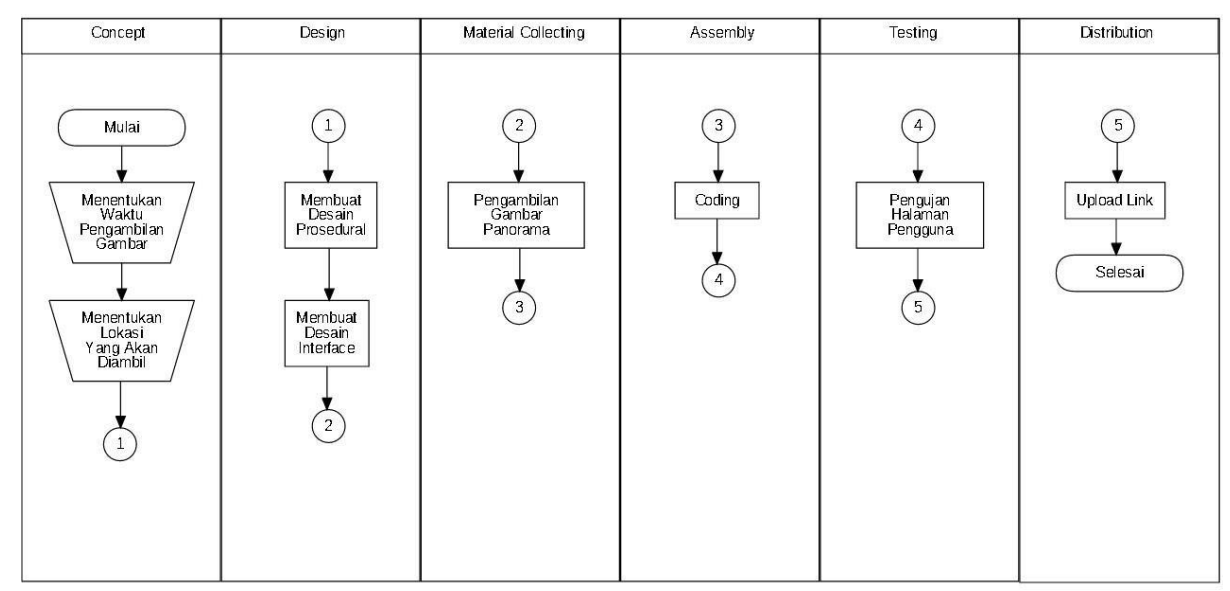

Gambar 1. Flowchart Pembuatan Virtual Tour

\subsection{Design (Desain)}

Setelah selesai pada tahap konsep, langkah selanjutnya adalah melakukan tahap design (desain). Tahapan desain adalah tahapan dimana sang peneliti menjabarkan dan menggambarkan bentuk dari aplikasi yang akan dibangun. Dengan ini peneliti membuat rancangan dalam pembuatan aplikasi agar dapat mengetahui kebutuhan dan kesesuaian dalam pembuatan aplikasi tersebut. Pada tahapan ini dibuat spesifikasi dalam perancangan sebuah aplikasi.

\subsubsection{Design Prosedural}

Pada tahap ini peneliti menggunakan flowchart untuk menggambarkan secara grafik mengenai langkah-langkah serta urutan prosedur dari sebuah aplikasi atau sebuah program sehingga dapat dilakukan secara terurut dari awal sampai akhir proses yang ingin dicapai. Berikut adalah tahapan dari design procedural :

\section{Flowchart Virtual Tour}

Menurut Jogianto, 2005 flowchart adalah "sebuah bagan atau chart yang menunjukan alir atau arus dari sebuah program secara logika dan prosedur". Flowchart virtual tour menjelaskan bagaimana cara mengakses aplikasi virtual tour. Dimulai dengan membuka aplikasi yang telah di unduh, lalu akan menampilkan sebuah halaman utama yang menampilkan menu virtual tour. Desain flowchart dapat dilihat pada gambar 2 dibawah ini. 


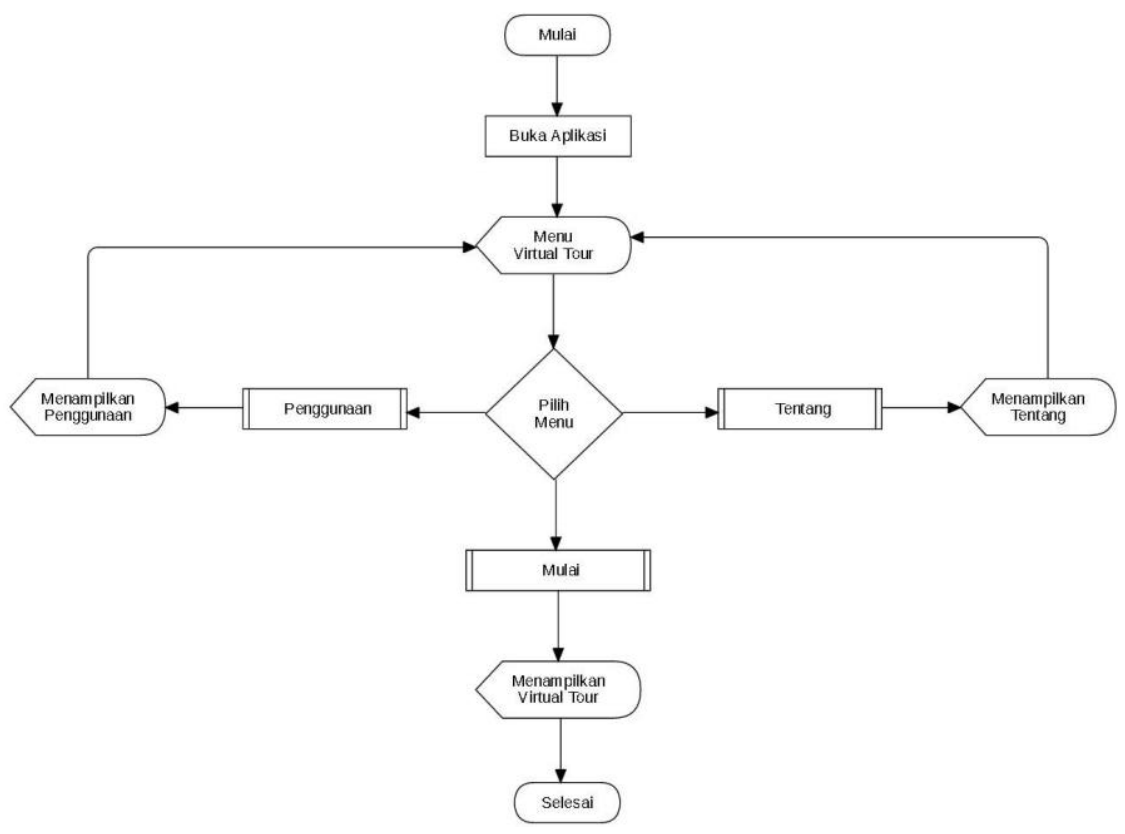

Gambar 2. Flowchart Virtual Tour

\section{Activity Diagram User}

Activity Diagram "menggambarkan workflow (aliran kerja) atau aktivitas dari sebuah sistem yang ada pada perangkat lunak" (Rachman, 2018). Activity Diagram berfungsi untuk menampilkan aktifitas yang terjadi ketika user mengakses halaman aplikasi dan bagaimana sistem merespon permintaan user. Aktivitas yang dapat dilakukan user dan sistem ditampilkan dalam bentuk gambar diagram yang ada dibawah ini.

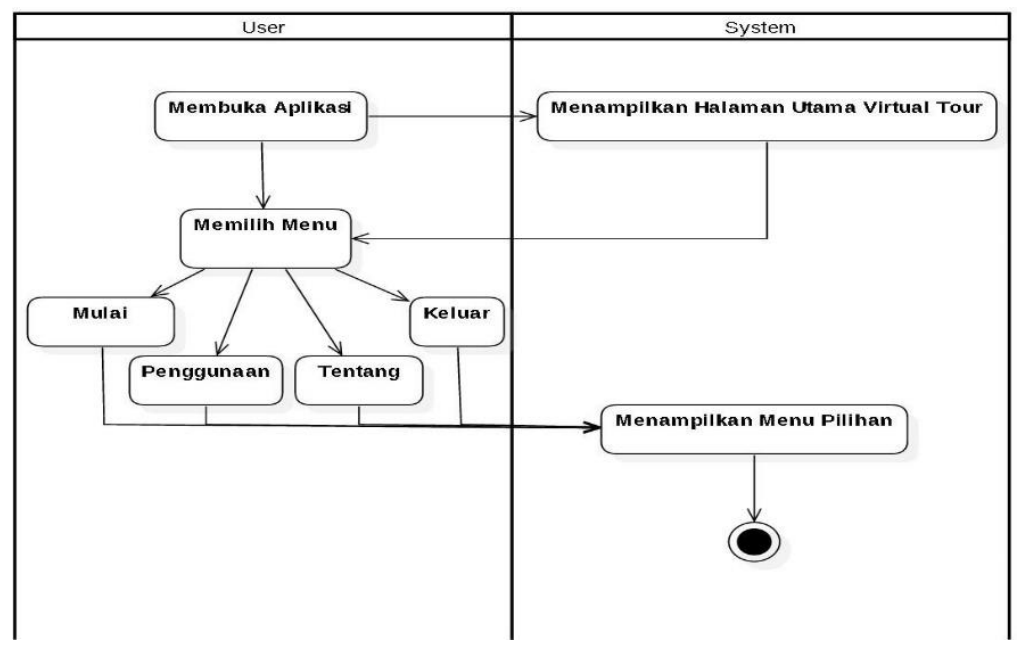

Gambar 3. Activity Diagram User

\section{Use Case Diagram}

Use Case Diagram adalah "sesuatu atau proses mempresentasikan hal-hal yang dapat dilakukan oleh aktor dalam menyelesaikan sebuah pekerjaan" [13]. Use case yang akan menjelaskan apa saja yang dapat dilakukan oleh user dalam menggunakan dan menampilkan halaman disetiap aplikasi virtual tour diperlihatkan pada Gambar 4. 


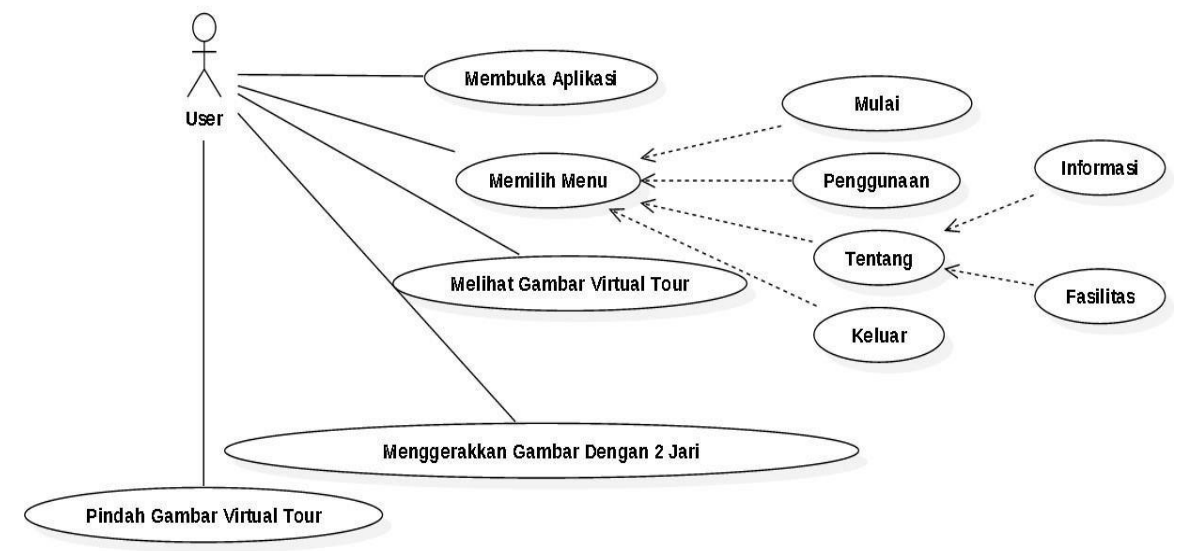

Gambar 4. Use case diagram virtual tour

\subsubsection{Design Interface}

Perancangan virtual tour membutuhkan rancangan antarmuka untuk user interface. Perancangan dilakukan dengan membuat ilustrasi atau biasa disebut dengan mockup. Mockup mempermudah perancang untuk mengetahui seperti apa model tampilan yang akan dibuat, sehingga elemen-elemen pada aplikasi dapat diketahui secara rinci dan jelas. Pada perancangan kali ini, aplikasi ini akan dibuat berbasis Android mobile dengan tampilan layar landscape. Berikut adalah rancangan interface dalam penelitian ini.

\section{Desain Interface Menu}

Rancangan halaman ini merupakan tampilan awal pengguna pada sistem. Pada halaman utama terdapat tombol-tombol yang memiliki fungsi masing-masing. Pada tombol Virtual Tour, user akan diarahkan ke halaman selanjutnya, yaitu memulai virtual tour yang berisi informasi Kampus Utama Universitas Bina Darma bersifat gambar panorama 360. Pada tombol Penggunaan akan diarahkan ke halaman yang berisi penggunaan aplikasi. Lalu ada tombol Keluar yang digunakan untuk keluar dari aplikasi dan terakhir adalah logo tanda tanya di atas pojok kiri yang mengarah ke bagian tentang informasi. Desain interface menu dapat dilihat Gambar 5.

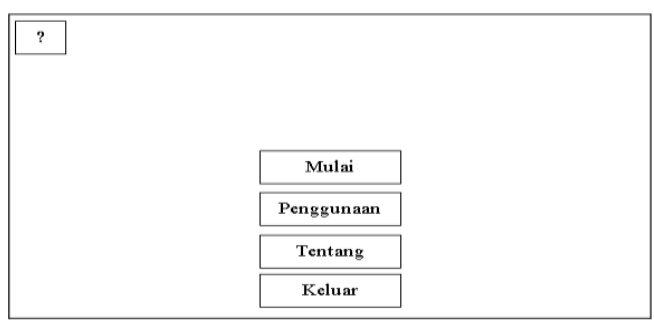

Gambar 5. Desain Tampilan Menu

\section{Desain Interface Virtual Tour}

Halaman ini merupakan rancangan tampilan gambar panorama 360 virtual tour. Dimana saat memilih menu virtual tour maka akan menampilkan gambar panorama 360 . Pengguna dapat menggerakkan gambar dengan touchscreen pada smartphone serta cara berpindah dari gambar satu ke gambar lainnya adalah dengan klik tombol merah pada gambar dan gambar akan berpindah secara berurutan. Desain interface virtual tour dapat 


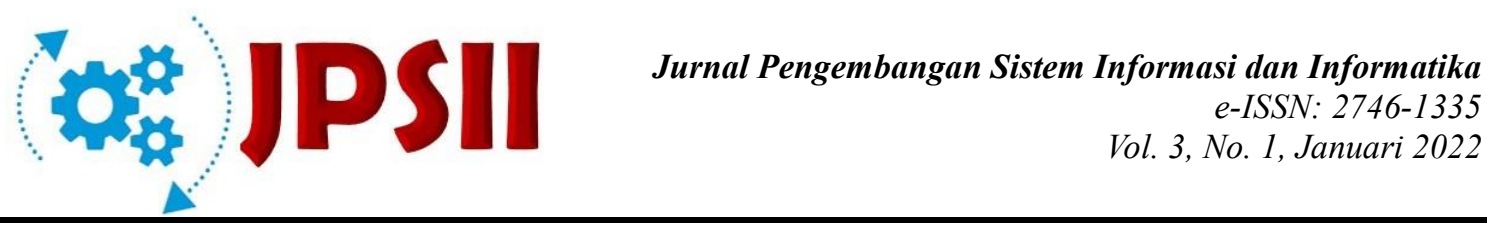

dilihat Gambar 6.

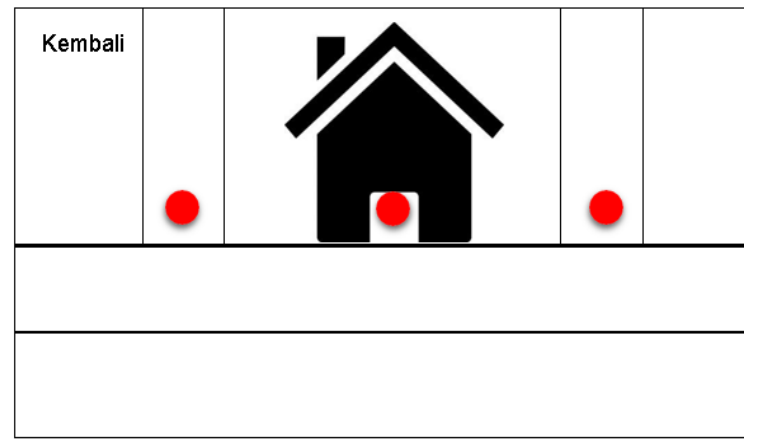

Gambar 6. Desain Pindah Scene ke Scene Lainnya

\subsection{Material Collecting (Pengumpulan Bahan)}

Material Collecting adalah tahapan pengumpulan materi atau bahan, yang dalam hal ini pembuatan aplikasi virtual tour Universitas Bina Darma ini menggunakan gambar sebagai materi utamanya. Gambar diambil dari beberapa lokasi dan dimasukkan ke dalam aplikasi virtual tour. Gambar yang diambil merupakan tempat yang penting atau memiliki nilai informasi untuk pengguna. Salah satu gambar panorama 360 yang diambil di area Universitas Bina Darma yang akan dimasukkan ke dalam aplikasi virtual diperlihatkan pada Gambar 7.

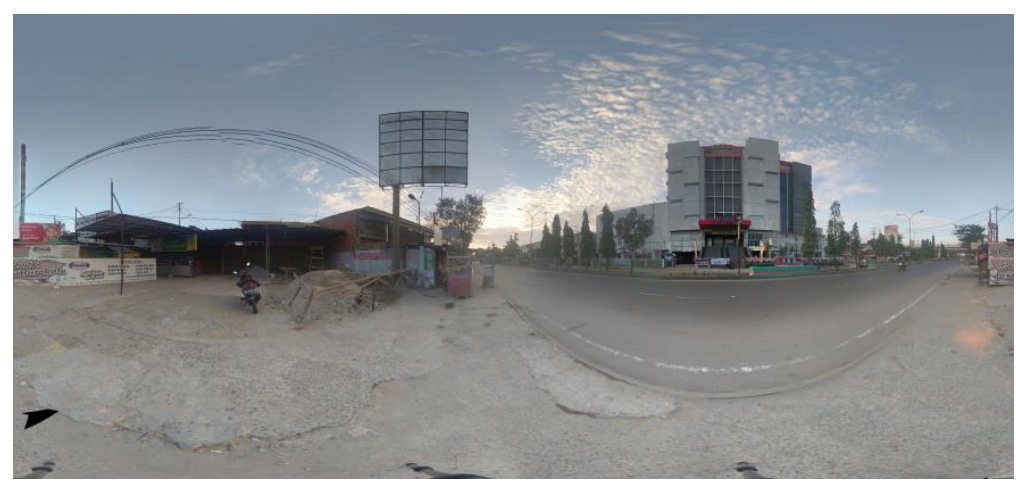

Gambar 7. Contoh Gambar Panorama 360 Universitas Bina Darma

\subsection{Assembly (Pembuatan)}

Tahap assembly (pembuatan) merupakan sebuah tahap dimana semua objek atau beserta bahan multimedia yaitu gambar panorama 360 yang telah diambil untuk virtual tour dibuat. Gambar-gambar yang telah di ambil dengan smarthphone akan secara otomatis tergabung menjadi satu yang artinya secara otomatis akan menjadi gambar panorama 360 . Setelah kumpulan gambar tiap lokasi telah menjadi gambar panorama 360 yang sesuai dengan kebutuhan suatu aplikasi virtual tour, maka berlanjut ke pembuatan aplikasi virtual tour untuk Universitas Bina Darma berbasis mobile Android menggunakan tools unity $3 D$ (Gede dkk, 2015). Berikut adalah hasil dari aplikasi yang dibuat :

\section{Tampilan Menu Awal}


Tampilan Menu Awal Aplikasi adalah tampilan yang paling pertama kali muncul ketika pengguna atau user mengakses sebuah aplikasi virtual tour setelah melakukan proses unduh. Tampilan Halaman menu awal dapat dilihat pada Gambar 8.

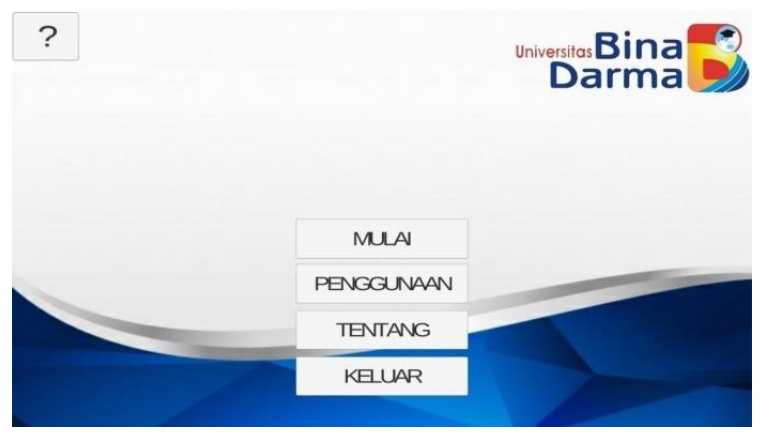

Gambar 8. Tampilan Awal Menu Virtual Tour

\section{Tampilan Virtual Tour}

Untuk melihat gambar panorama 360 secara penuh dapat digerakkan smartphone (dibutuhkan sensor gyro pada smartphone). Pada gambar terdapat lingkaran merah yang dapat ditekan untuk berpindah gambar dari gambar yang dibuka saat ini ke gambar selanjutnya secara berurutan. Terdapat "tombol kembali" tepat diatas pojok kiri untuk kembali ke halaman menu utama. Tampilan awal virtual tour Universitas Bina Darma dapat dilihat pada Gambar 9, tampilan virtual tour ruang aula diperlihatkan pada Gambar 10, dan ruang perpustakan diperlihatkan pada Gambar 11.

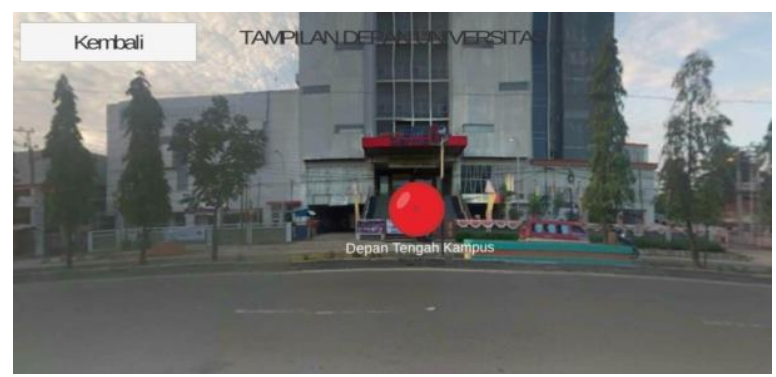

Gambar 9.Tampilan Mulai Virtual Tour

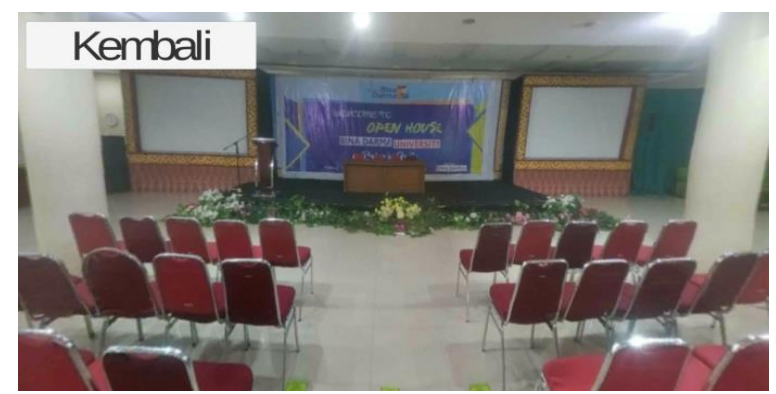

Gambar 10. Tampilan Ruang Aula 


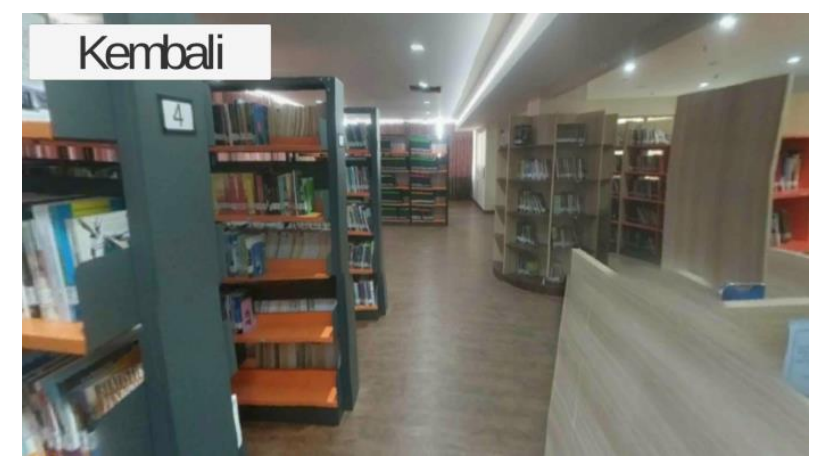

Gambar 11. Tampilan Ruang Perpustakaan

\subsection{Testing (Pengujian)}

Tahap testing (Pengujian) merupakan tahap dimana setelah aplikasi dibuat dilanjutkan ke tahapan menguji kinerja dari aplikasi yang telah dibuat. Pengujian sistem yang digunakan pada aplikasi virtual tour Universitas Bina Darma ini adalah metode blackbox testing. Metode Blackbox testing merupakan "salah satu metode yang mudah digunakan karena hanya memerlukan batas bawah dan batas atas dari data yan di harapkan, Estimasi data uji dapat dihitung melalui banyaknya field data entri yang akan di uji, aturan entri yang harus dipenuhi serta kasus batas atas dan batas bawah yang memenuhi" (Cholifah, 2018)

Pengujian dilakukan pada aplikasi virtual tour menggunakan perangkat smartphone. Hasil pengujian fungsi pada halaman pengguna dapat dilihat pada Tabel 1 .

Tabel 1. Pengujian Aplikasi Virtual Box

\begin{tabular}{llrl}
\hline No. & Fungsi & Hasil & Keterangan \\
\hline 1. & Mengakses Aplikasi. & $\checkmark$ & Berhasil \\
2. & Menampilkan Halaman Menu Utama. & $\checkmark$ & Berhasil \\
3. & Menampilkan Halaman ? & $\checkmark$ & Berhasil \\
4. & Menampilkan Halaman Penggunaan. & $\checkmark$ & Berhasil \\
5. & Menampilkan Halaman Tentang. & $\checkmark$ & Berhasil \\
6. & Menampilkan Halaman Informasi. & $\checkmark$ & Berhasil \\
7. & Menampilkan Halaman Fasilitas. & $\checkmark$ & Berhasil \\
8. & Menampilkan Halaman Gambar & $\checkmark$ & Berhasil \\
& Panorama 360. & & \\
9. Gambar Bergerak Dengan sentuhan & $\checkmark$ & Berhasil \\
10. & Gayar. & & \\
& Dengan Tombol Lingkaran Merah. Berganti Secara Berurutan & $\checkmark$ & Berhasil \\
\hline
\end{tabular}

\subsection{Distribution (Distribusi)}

Setelah melalui tahap pengujian atau testing dan memastikan semua fungsi telah berjalan dengan semestinya maka aplikasi dianggap layak untuk didistribusikan. Proses distribusi dalam hal ini adalah dengan menggunggah sebuah aplikasi yang telah dibuat dan diuji.

\section{Kesimpulan}

Hasil dari penelitian ini adalah aplikasi virtual tour Universitas Bina Darma berbasis android. Aplikasi virtual tour ini digunakan sebagai media informasi dan promosi Universitas Bina Darma berbasis gambar panorama 360 yang dibuat dari Unity $3 D$ yang memiliki total gambar yaitu 26 gambar panorama 360. Dengan adanya aplikasi ini Universitas Bina Darma dapat lebih memperkenalkan lingkungan kampus beserta semua 


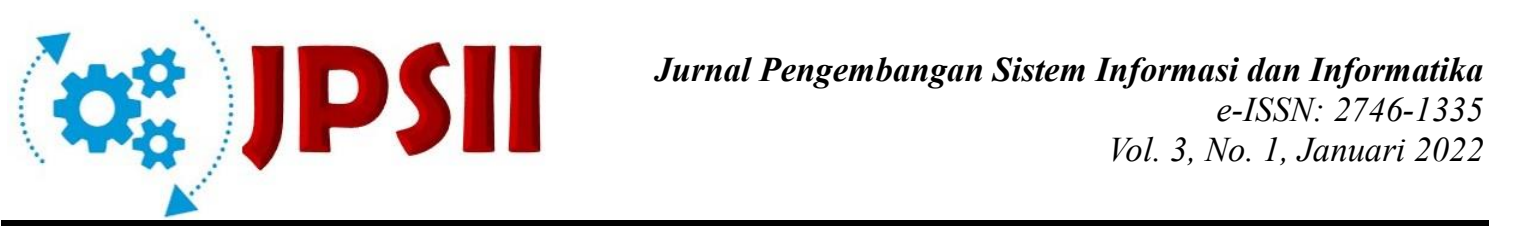

fasilitasnya baik kepada calon mahasiswa, mahasiswa maupun lingkungan masyarakat.

\section{Referensi}

Daud, F. R., Tulenan, V., \& Najoan, X. B. (2016). Virtual Tour Panorama 360 Derajat Kampus Universitas Sam Ratulangi Manado. E-journal Teknik Informatika, 1-6.

Pamoedji, Kurniawan, A., Setiyowati, Maryuni, Sanjaya, \& Ridwan. (2017). Mudah Membuat Game Augmented Reality (AR) dan Virtual Reality (VR) dengan Unity 3D. PT. Elex Media Komputindo.

H. Budiman, "Peran Teknologi Informasi Dan Komunikasi Dalam Pendidikan Haris Budiman.," J. Pendidik. Islam, Vol. 8, No. I, Pp. 31-43, 2017.

M. O. Fitri, "Rancang Bangun Aplikasi Virtual Tour Monumen Mandala Berbasis Android," Inform. Sains Dan Teknol., Vol. 1, No. 1, 2016.

H. W. Wulur, S. Sentinuwo, And B. Sugiarso, “Aplikasi Virtual Tour Tempat Wisata Alam Di Sulawesi Utara," J. Tek. Inform., Vol. 6, No. 1, Pp. 1-6, Nov. 2015.

H. Kusniyati And N. S. P. Sitanggang, "Aplikasi Edukasi Budaya Toba Samosir Berbasis Android," J. Tek. Inform., Vol. 9, No. 1, Pp. 9-18, 2016.

Mustika, E. Prasetya, A. Sugara, And M. Pratiwi, "Pengembangan Media Pembelajaran Interaktif Dengan Menggunakan Metode Multimedia Development Life Cycle," $J$. Online Inform., Vol. 2, No. 2, Pp. 121-126, 2017.

M. Linarwati, A. Fathoni, And M. M. Minarsih, "Studi Deskriptif Pelatihan Dan Pengembangan Sumberdaya Manusia Serta Penggunaan Metode Behavioral Event Interview Dalam Merekrut Karyawan Baru Di Bank Mega Cabang Kudus," J. Manage., Vol. 2, No. 2, 2016.

R. G. Guntara And M. Yakub, "Pembangunan Aplikasi Know Your Customer Digital Untuk Mencegah Penipuan Pada Fintech Lending Memanfaatkan Api Clarifai Dan Blinkid Android Sdk," J. Ilm. Komput. Dan Inform., Vol. 7, No. 1, Pp. 19-26, 2018.

Sugiyono, Metode Penelitian Pendidikan Pendekatan Kuantitatif, Kualitatif, Dan R\&D. Bandung: Alfabeta, 2016.

A. S. Kusuma And I. G. S. E. Putra, "Rancang Bangun Sistem Penjadwalan Wawancara Mahasiswa Baru Stmik Stikom Indonesia," J. Ilm. Teknol. Inf. Asia, Vol. 11, No. 2, P. 139, Aug. 2017.

S. Nurajizah, "Implementasi Multimedia Development Life Cycle Pada Aplikasi Pengenalan Lagu Anak-Anak Berbasis Multimedia," J. Prosisko, Vol. 3, No. 2, P. 6, 2016.

H. Jogianto, Analisis \& Desain Sistem Informasi: Pendekatan Terstruktur Teori Dan Praktik Aplikasi Bisnis, Iii. Yogyakarta: Andi Offset, 2005.

A. N. Rachman, "Sistem Informasi Wisata Di Ampera Waterpark," J. Siliwangi Seri Sains Dan Teknol., Vol. 4, No. 2, Pp. 87-92, 2018.

"Perancangan Sistem Informasi Rental Mobil Berbasis Web Pada Pt.Apm Rent Car," Vol. 2, P. 14, 2018.

I. D. Gede, W. Dhiyatmika, I. K. Gede, D. Putra, N. Made, And I. Marini, "Aplikasi Augmented Reality Magic Book Pengenalan Binatang Untuk Siswa Tk," Lontar 
Komput., Vol. 6, No. 2, Pp. 120-127, 2015.

W. N. Cholifah, S. M. Sagita, And S. Knowledge, "Pengujian Black Box Testing Pada Aplikasi Action \& Strategy Berbasis Android Dengan Teknologi Phonegap," J. String, Vol. 3, No. 2, Pp. 206-210, 2018.

\section{Copyrights}

Copyright for this article is retained by the author(s), with first publication rights granted to the journal.

This is an open-access article distributed under the terms and conditions of the Creative Commons Attribution license (http://creativecommons.org/licenses/by/4.0/) 